\title{
LINGERIE AND MORALITY: \\ GENERATION Y KAZAKHSTANI WOMEN'S ATTITUDE TOWARD LINGERIE
}

\author{
Gulnara Z. Karimova \\ American University of Ras Al Khaimah, UAE \\ Aidana Rassilbay \\ Kcell Corporation, Kazakhstan \\ Daniel A. Sauers \\ Winona State University, Minnesota, USA
}

\begin{abstract}
This paper explores the tension between 'resistance' and 'obedience' manifested in narratives concerning lingerie expressed by Kazakhstani women born in the 1980s and 1990s. The attitude of Kazakhstani women toward lingerie and the way they formulate these attitudes illustrate the complex strategies used to negotiate and construct femininity. Such strategies reveal two contradictory beliefs: that of empowerment and suppression. We argue that these contradictory beliefs are the result of the respectable norms of female sexuality being imposed through the mechanisms of power to keep women in line with the requirements of the existing socio-economic structures. In such structures, the labels "vulgar," "provocative," and "dissolute" are given to certain types of lingerie and are opposed to those of "modest," "restrained," and "decent." The qualities mentioned as crucial by Kazakhstani women in defining femininity: "kindness," "affection," tenderness," and "modesty" reflect what Friedrich Nietzsche called the 'slave' morality that celebrates 'passivity' and "weakness."
\end{abstract}

Keywords: Femininity, Lingerie, Kazakhstan, Attitude, “Slave” morality, “Docile” bodies.

DOI: http://dx.doi.org/10.15549/jeecar.v4i1.149

\section{INTRODUCTION}

The underlying motivation for conducting this research emerged when a leading Kuwaiti lingerie company entered the Kazakhstani market. Responsible for developing the advertising concept, the authors had to find answers to the questions: "What is the attitude of Kazakhstani women toward lingerie and how it is used for constructing their femininity?" While there are a few studies that address these questions within the so-called "Western" context (e.g., Valuckaite, 2014; Wood, 2016), little is known about the subject within the context of Central Asia, particularly Kazakhstan. As Buckley (2002) writes, "Female perceptions of style and fashion, and attitudes to luxury, beauty care, and physical perfection, are largely 
uncharted territory" (p. 290).

This paper attempts to fill the existing gap by conducting semi-structured, in-depth interviews with thirty-two Kazakhstani women between the ages of twenty-five to thirty-four. The study aims to examine Kazakhstani female consumers' attitudes toward lingerie and to add to our knowledge of Kazakhstani women's expression of their femininity through lingerie.

\section{'Lingerie'}

Despite the fact that the French word 'lingerie' has the same meaning as 'underwear,' in English-speaking countries, the expression is often associated with more attractive or sensuous underwear. Edwards (2016) assumes that underwear and lingerie have one distinction: the reason it is worn. Lingerie is sometimes worn underneath the clothes, although, it is not typically selected for practicality or convenience. Lingerie is usually selected based on its 'beauty.' Underwear is worn for feasibility and convenience by both genders, while lingerie usually is worn by women. Moreover, underwear is not as expensive as lingerie and is made of inexpensive cotton, while lingerie is typically made from more costly materials such as silk, satin, and lace. As Edwards (2016) puts it, "all lingerie is underwear, but not all underwear is lingerie" $(\S 1)$. However, the boundary between attractive and unattractive, expensive and cheap is vague.

Our research revealed that some interview respondents referred to lingerie as a mere matching of a bra and knickers that are easily acquired in outlets typically located in the shopping malls of Almaty (the largest city in Kazakhstan), such as Etam, La Senza, Milavitsa, Women's Secret, Sharm, Intimissimi, Invisible Secret, Avrora, and Agent Provocateur or in virtual on-line shops.

As Wood (2016) asserts, "there is clearly a degree of negotiation with, and slippage between, the categories of 'everyday underwear' and 'sexual lingerie"' (p. 12). Thus, the definition of 'lingerie' is employed in this paper in quite general terms related primarily to underwear items.

\section{Theoretical Framework}

The purpose of this exploratory study is to critically examine the relation between the attitude of Kazakhstani women toward lingerie and the perception of their femininity. This purpose has formed the basis for creating the interview guide for respondents and further determined the information valuable for the analysis section (Theoretical Framework, 2016). The study is designed "to understand the respondent's point of view rather than make generalizations about behavior" (Livesey, 2007, p.1).

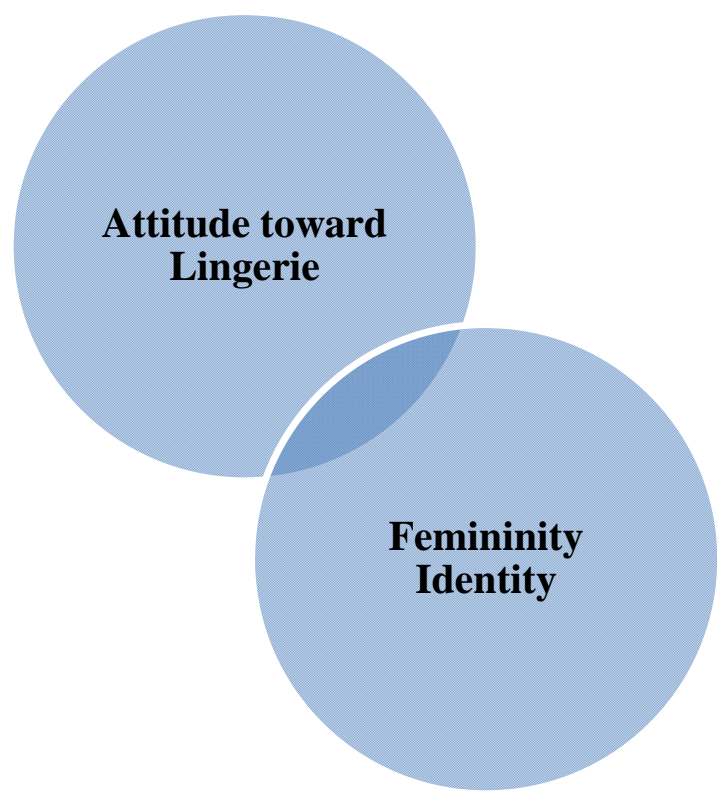

Diagram 1: Theoretical Framework

\section{Femininity Gender Identity}

Femininity or masculinity - one's gender identity - refers "to the degree to which persons see themselves as masculine or feminine given what it means to be a man or woman in society" (Burke, Stets \& Pirog-Good, 1988). Femininity as one gender identity can be described as "the quality or nature of the female sex" (Femininity, 2016). Stoller (1980) explains that femininity is "natural appearing, unselfconscious, ordinary, normative behavior typically of and expected from girls and women and not of boys and men." (p. 128). Lingerie is usually expected to be worn by women, thus, examining the attitude of women toward such an exclusively female item as lingerie may shed a little light on how women construct their gender identity and femininity.

\section{Attitude}


Attitude can be described as the outcome of learning experience that involves a cognitive and emotional factor (Montazeri, Sharifinia, Hadian, Mohammadbagher, \& Bazarkhak, 2013). Attitude is "a mindset or a tendency to act in a particular way due to both an individual's experience and temperament" (Pickens, 2005, p. 44). From the marketing perspective, an attitude in many cases precedes the action. Therefore, it was paramount before entering Kazakhstani lingerie market and launching marketing communications campaign to learn the beliefs and feelings Kazakhstani women hold about lingerie, the perception of their gender identities and the role that lingerie plays in the construction of their femininity. The term attitude thus is utilized to denote values, thoughts, opinions and beliefs (Blankson, 2005).

\section{THE METHODOLOGY}

An exploratory design was adopted to extract detailed information about the values, feelings, and beliefs Kazakhstani women hold about lingerie and femininity. As exploratory design "can address different kinds of inquiry (what, why, how)" (Research Design, 2016, §33), it is the most suitable design for this study as there has been little investigation into the perception of femininity among Kazakhstani women and their attitude to lingerie.

The data for this paper is drawn on from thirty-two interviews conducted in FebruaryApril of 2016. In seeking participants, we aimed to speak to a wide range of women of various ethnicities in Almaty. With participants' permission, audio recordings of the interviews were made to guarantee accurate transcription. During the initial phase of the interview, the participants were reminded of the purpose of the study, research procedure, and their right to refuse to participate at any time during the interview. The interviews were conducted in Russian and later transcribed and translated into English.

Individual interviews were conducted in person, with participants recruited through a range of 'snowball' sampling methods. The technique is appropriate for various exploration purposes and especially pertinent at the point when the center of study is a delicate issue, conceivably concerning a moderately private matter (Bryman, 2001, p. 141). It was deemed that 'lingerie' might be perceived as such a delicate matter by some respondents and the assumption proved to be correct. Thus, trust gained by the researchers through 'snowball' sampling has induced the participants to share information during the interview that is more intimate. At the same time, there was awareness that 'snowball' sampling could lead to a degree of 'sameness' between the cultural identity of the researchers and that of the interviewees (Browne, 2005).

The interview was divided into two parts: describing the concept of femininity and revealing attitudes toward lingerie. In the first part, the questions related to femininity and women's perceptions of themselves were included. The second part of the interview comprised questions about styles of lingerie that women preferred to wear, the colors and types of materials they favored, and the attributes that they prioritized while choosing lingerie. This part also included six images of different types of lingerie in order to elicit information and facilitate the discussion about preferences and attitudes of women toward lingerie. Different designs of lingerie were arbitrary selected by the researchers to reflect the typical perceptions of both so-called 'simple' cotton and 'sexy' lace lingerie.

Although, there is no the strict designation of the sample size in qualitative study Adler and Adler (2012) claim that the number of individuals required to make a sufficient sample for a qualitative research can vary from one to a hundred or more. Their advice is to choose a number of interviewees "in the broad range of between a dozen and 60 , with 30 being the mean" (p. 10). Thus, this study employs thirtytwo females from what has been termed Generation Y, which is close to the recommended mean. However, we do not claim that the selected sample of women is representative of or can be generalized to the entire Kazakhstani female population.

\section{ANALYSIS}

The analysis of the interviews was performed by the use of Maxqda12 software, and the grounded theory approaches are applied. Grounded theory can be described as "a set of rigorous research procedures leading to the emergence of conceptual categories. These concepts/categories are related to each other as a theoretical explanation of the action(s) that continually resolves the main concern of the participants in a substantive area" (What is 
grounded theory, 2008, §1).

To analyze the collected data a few steps have been undertaken. First, all data was transcribed. Second, the process of labeling relevant words, sentences, and phrases was carried out. Third, information was separated into segments. For example, such codes as 'comfort,' 'beauty,' and 'practicality' were assigned accordingly to the phrases. Then, the most important codes were grouped together to represent the dominating themes.

\section{RESULTS}

Four dominating themes were revealed, two each under women's perceptions of femininity ("well-groomed" and "meek and modest") and two under women's attitude toward lingerie ("beauty and comfort" and "modest and discrete"). Next, each dominating theme is described in detail.

\section{Describing the Concept of Femininity}

The interviewees held different opinions about the concept of femininity. For some respondents, 'external' features, such as "wellgroomed" and "beautiful," seemed to occupy a central position in their perception; others gave importance to 'internal' characteristics associating femininity with such qualities as "tenderness," "gentleness," and "care"; and some were prone to combine both while defining the notion of femininity and woman.

\section{"Well-groomed" Woman}

Interviewed participants mostly identified 'exterior' features, such as "being beautiful" and "being well-groomed" as key features essential for a woman. The word "well-groomed" (ухоженная) was frequently used in the sentences responses of the participants, or respondents. The responses below are representative of participants' views:

A woman should be beautiful, well-groomed, and always with a manicure. The hair and all things should be as it should be (Akerke, 28).

First and foremost, to be a woman, probably, means not to be good, open, affectionate, and beautiful, but well-groomed (Albina, 34).
Ugly women do not exist. The main thing is that woman should be well-groomed and take care of herself (Kseniya, 26).

A woman should be feminine: gentle, attentive to herself and wellgroomed (Dinara A., 27).

The sociological survey conducted by Forbes.kz (2016) among one thousand people between the ages of fourteen to twenty-nine years from fourteen regions of Kazakhstan including the cities of national significance such as Almaty and Astana supports the findings of the current study. According to the survey, $76.1 \%$ of respondents find it important to look good (The things vital for the Kazakhstani youth, 2016).

It is evident that Kazakhstani women are concerned about their appearances. The respondents pointed out that they try to take care of themselves to look "well-groomed" even if they have a busy schedule, as reflected in the following statements:

First of all, I love to take care of myself, starting from my hair and skin and all the way to my underwear (Gulmira, 26).

I try to take care of myself, but do not always have enough time, because of my busy schedule (Svetlana, 25).

Buckley (2002) claims that the aspiration of women in Central Asia to follow beauty and take care of themselves is the result of the influence of Western values and trends. Upon closer examination, it becomes evident that women seem to be willing to modify their bodies and looks. The ideals of the female body according to which women adjust their bodies, are propagated in the advertisements, fashion catalogs, magazines and other mass media vehicles. The bodies are "normalized" and modified to fit the established standards. The body becomes disciplined, "less socially oriented and more centripetally focused on selfmodification" (Bordo, 1993, p. 166). The body becomes "docile," that is it "may be subjected, used, transformed, and improved" (Foucault, 1984, p. 180).

\section{"Meek" and "Modest" Woman}

The qualities regularly used to describe femininity by some participants reflected more 
internal qualities, such as "tenderness," "gentleness," "care," and "modesty." Some typical responses include:

Femininity always implies grace, tenderness and sincerity (Dinara T., p. 26).

First, a woman should be feminine and she must not forget her mission: Be gentle, thoughtful, and considerate (Dzhamilya, p. 27).

Buckley (2002) asserts that Post-Soviet Central Asian women have to possess certain female qualities in order to perform their traditional female duties. It is expected that individuals have appropriate gender differences such as "weakness" in women and "strength" in men (Buckley 2002). These gender differences are reflected in the following statements:

Certainly, every woman should underline her beauty, tidiness and good behavior (Gulmira, 26).

A woman should be sensitive, responsive, and kind (Milena, 27).

A woman should be feminine and she should not forget her mission. She should be affectionate, caring, and attentive (Dzhamilya, 27).

Kindness, humility, and affection are the very traits valued by what Nietzsche (1973) calls "slave" morality. Master morality values pride, strength, adventure, danger, and nobility. These two types of moral strands are in constant struggle, which is expressed in the language, narratives, and various practices. It seems the notion of lingerie as a type of intimate language is not an exception in hosting the conflicting forces.

\section{Revealing the Attitude toward Lingerie}

\section{"Beauty" and "Comfort"}

In choosing lingerie, most women were inclined to buy "comfortable" lingerie that is at the same time "beautiful." The majority of respondents prefer black lace push-up lingerie and "strict" lingerie in subdued colors.

One word that was used frequently in the description of lingerie that interviewees liked was "beautiful." The term "beautiful" in relation to underwear garments was primarily opposed to other adjectives such as "sexy," "vulgar," "provocative," and "indecent," and seemed to sum up a "cute," "gentle," and "modest" style of lingerie that is "safe and respectable, valued primarily for its inoffensiveness" (Wood, 2016, p. 16). In a way, the word "beautiful" used by Kazakhstani women was equivalent to the word "nice" used by the interview participants in the research conducted among British women by Wood (2016). Both connote "a pretty, soft version of femininity, which is special and different from the everyday, but at the same time, carries no risk of appearing to be distasteful" (Wood, 2016, p. 16).

\section{"Modest" and "Discreet" Lingerie}

Modesty appears to be an important characteristic for the woman interviewed. Respondents of both ethnicities, Kazakh and Russian, say that they usually choose lingerie that is "gentle," "modest," and "discreet," as reflected in the following responses:

I was brought up in such a way that I cannot wear frank lingerie....for me, the simpler the better. I choose underwear, which is very modest (Akerke, 28).

My attitude is modest; I do not like to choose lingerie with my boyfriend. I do not like openness (Dinara R., 26).

As we are a Muslim country, we have boundaries that we should mind while choosing lingerie...no provocativeness, no frankness (Dinara T., 26).

The picture depicting a model wearing stockings and lacy lingerie was considered "vulgar" and "indecent" by the majority of the interviewees.

I would never put on such lingerie as on this pictures; too frank for me and looks too dissolute (Samal, 27).

In this picture, she is "on a hunt" (Kseniya, 26).

To understand why the picture depicting a model wearing stockings and lacy lingerie was labeled by the Kazakhstani women as "vulgar," "immoral," and "indecent" one must consider first, the historical background of Kazakhstani society. Sarybekova (2004) notes that the Kazakh national pedagogics widely used in upbringing of teenagers such senses as "honor," "pride," and "chastity." Especially girls have had 
the heavy responsibility of preserving their "chastity." Maiden honor in women has been associated with purity, nobility and goodwill. These values are still promoted in the society (Sarybekova, 2004/2016, pp. 120-121), as reflected in the following statements:

I judge using my own background. Our family is such that we have never behaved in overfamiliar manner, [...] that could disgrace our parents. Such is Kazakh mentality: upbringing should stress modesty, especially for a girl (Roza, 27).

As we possess kind of Asian type of mentality, even our men are ashamed to present lingerie as a gift. Our upbringing does not allow accentuating attention on lingerie (Dinara G., 31).

Within this discourse of repression of sexuality, such values as "modesty," "obedience," and "decency" form morality where women are praised for enacting "passive" roles.

There is a parallel between the dominating themes related to women's perceptions of femininity (i.e., "well-groomed"; "beauty and comfort") and women's attitude toward lingerie (i.e., "meek and modest"; "modest and discrete").

Modesty is the dominating theme in the narratives about lingerie expressed by the participants. Why is this? A quick look back at the history of lingerie reveals that "when the First World War broke out, women found themselves filling the men's work roles, creating the demand for more practical undergarments." Minute technique, introduction of more comfortable and practical underwear garments, enabled a slightly more efficient mode of exploitation of the female body. That brings us back to Foucault's examination of "mechanics of power" defined as "how one may have a hold over others' bodies, not only so that they may do what one wishes, but so that they may operate as one wishes, with the techniques, the speed, and the efficiency that one determines" (Foucault, 1984, p. 182). Now, women are enabled to not only work, but also work more effectively. Utility is the essence of slave morality (Nietzsche, 1973, p. 122): the good is what is most useful for the whole community; comfortable (Wood, 2016) and practical (Valuckaite, 2014) underwear garments.
Obedience to someone's will is vital for slave morality. The submissiveness to a man's power seems to be conventional among the interviewed participants and is reflected in the following responses:

If my husband in the future will tell me, "Do not wear it, it is not beautiful, it does not suit you" I will not wear it (Moldir, 25).

If your husband treats you as you desire, you will try to make something nice and express it with the beautiful underwear garments. It depends on the man and on how much he wants it (Roza, 27).

I consider that lingerie depicted on the pictures five and six is too vulgar. Maybe it is sexy, but I would wear it only if my husband would force me to (Dinara T., 26).

The passages like these make one doubt in the emergence of empowering sexual culture of women who are free to "choose" to present themselves as sexually independent individuals (McRobbie, 2001, 2004; Gill, 2003). Yet, one may sense the voices of residence, however scarce they are, in the following statement:

I think that it not correct to wear lingerie for someone else. You are wearing it for yourself, not for somebody (Gulzat, 31).

Thus, it is evident (from post-feminist perspective) that sexual culture of women is ambivalent: saturated with resistance and at the same time obedience.

\section{CONCLUSION}

In this study, we have examined the ways in which the perception of femininity is reflected in the narratives of Kazakhstani women about themselves and about lingerie. An analysis of these narratives revealed a tension between resistance and obedience. This interpretation draws its inspiration from Foucault's (1984) and Nietzsche's (1973) notions of "docile" bodies and "slave" morality.

Throughout the thoughts, feelings, and beliefs toward lingerie and femininity expressed by interviewed women, the word modesty seemed to be a common denominator within their narratives. They preferred to buy and wear modest lingerie; often they perceived themselves as modest, and they allocated a 
great value to such traits as modesty in women. Although, Kazakh proverbs, fairy tales, and other artifacts of cultural heritage may celebrate modesty (e.g., If you are great, be modest [Если ты велик - будь скромен], or Modesty adorns a man [Скромность красит человека]) for Nietzsche (1973) it is the trait pertinent to slave morality which denies humans' instinctually based energy. It postulates that sex, as a base nature, should be suppressed. Perhaps this is the reason why the majority of respondents discarded the images of sexually prominent lingerie as "vulgar" and "immoral." Slave morality thrives on the traits that facilitate domination: tenderness, kindness, gentleness, and modesty. This domination can be exercised through various disciplines. These disciplines "were different from slavery because they were not based on a relation of appropriation of bodies; indeed the elegance of the discipline lay in the fact that it could dispense with this costly and violent relation by obtaining the effects of utility at least as great" (Foucault, 1984, p. 181). The comfort and practicality of lingerie underlined not only by Kazakhstani but also British (Wood, 2016) and Danish (Valuckaite, 2014) women demonstrate the elegance of the discipline at work. Not only that but also the dedication of many Kazakhstani women to the modification of their bodies in praise of the "well-groomed" mode of female existence exhibits the construction of "docile" bodies. These bodies are amended in gyms and beauty salons to turn into women perfect to perform their jobs at work and at home.

Certainly, Foucault's and Nietzsche's philosophical thoughts are only some of possible ways to understand the tension/conflict between the spirits of empowerment and subjugation. This framework can also be used to question our own work that involved generating promotional materials for a lingerie producer. The advertising and marketing communication project initiated had as its purpose the promotion of lingerie in the Kazakhstani market. It is impossible not to reflect on our thought process behind the development of this marketing campaign. The search for the resolution of the tension between empowerment and subjugation, and between resistance and obedience was extended to the visual representations of femininity in the promotional materials. The awareness that the norms promoted through advertising imposed a more cautious visual representation of
Kazakhstani females in the lingerie advertising campaign. On the one hand, there was a desire to undertake a cultural shift toward representing women as "active" sexual agents. On the other hand, the attempt to avoid the risk of being misinterpreted as "vulgar" and "provocative" could lead to further proliferation of the submissive image of women so steadily established in the dominant discourse of female sexuality.

\section{REFERENCES}

Adler, P.A., and Alder, P. (2012) in How many qualitative interviews is enough?: Expert voices and early career reflections on sampling and cases in qualitative research [Working Paper] Baker, S.E., and Edwards, E. (Eds.) National Centre for Research Methods, 8-11. Retrieve May 9, 2016, from http://eprints.brighton.ac.uk/id/eprint/116 32

Blankson, S. (2005). What Is Your Mental Attitude? Attitude, 3-4. Libraries Australia.

Bordo, S., (1993). Unbearable weight: Feminism, western culture, and the body. Berkeley: University of California Press.

Browne, K. (2008). Culture and Identity. Sociology for AS AQA. 39. Polity Press, UK.

Bryman, A. (2001). Social Research Methods (3rd ed). Oxford: OUP, UK.

Buckley, M. (2002). Post-Soviet Women: From the Baltic to Central Asia. Cambridge University Press, UK.

Burke, P.J., Stets, J.E., and Pirog-Good. M. A. (1988). Gender Identity, Self-Esteem, and Physical and Sexual Abuse in Dating Relationships. Social Psychology Quarterly, 51(3), 272-285.

Daurtseva, K. (2013). Kazakhstan Underwear Market. Retrieved February 10, 2016, from http://kristinadaurtseva.blogspot.com/201 3/10/blog-post_8.html (Original work written in Russian)

Edwards, K. (2016). What Is the Difference between Underwear and Lingerie? Retrieved February 10, 2016, from http://www.wisegeek.com/what-is-thedifference-between-underwear-andlingerie.htm

Foucault, M. (1984). Practices and Knowledge in Rabinov, P. (Ed.). The Foucault Reader, Pantheon Books, New York, USA 
Femininity [Def. 2]. (2016). Merriam-Webster Online. In Merriam-Webster. Retrieved April 12, 2016, from http://www.merriamwebster.com/dictionary/femininity.

Gill, R., 2003. From sexual objectification to sexual subjectification: The resexualisation of women's bodies in the media. Feminist Media Studies, 3(1), 100-106.

Jones, C., Peskin, H. \& Livson, N. (2011). Men's and Women's Change and individual differences in change in femininity from age 33 to 85: Results from the intergenerational studies. Journal of Adult Development, 18(4), 155-163.

Livesey, C. (2007). Sociological research skills: Research methods: Focused (semistructured) interviews. Retrieve April 12, 2016, from http://www.sociology.org.uk/methfi.pdf

McRobbie, A. (2001). Feminism, postmodernism, and the "real me." In: M.G. Durham and D. Kellner, eds. Media and cultural studies: KeyWorks. Oxford: Blackwell, 520-532.

McRobbie, A. (2004). Post-feminism and popular culture. Feminist Media Studies, 4 (3), 255264.

Montazeri, B., Sharifinia, K., Hadian, H., Mohammadbagher, S., \& Bazarkhak, S. (2013). The Impact of Attitude on Consumer Behavior. Universal Journal of Management and Social Sciences, 3(3), 7277.

Nietzsche, F. (1973). Beyond Good and Evil. Translated by R. J. Hollingdale, Harmondsworth: Penguin Books.

Pickens, J. (2005). Attitudes and perceptions. In Borkowski, N. Organizational Behavior in Health Care, Sudbury: MA: Jones and Bartlett Publishers, 43-76. Retrieved April 12, 2016 from http://healthadmin.jbpub.com/Borkowski/c hapter3.pdf.

Research Design (2016). Research Guides of University of Southern California Libraries. Retrieved April 12, 2016, from http://libguides.usc.edu/writingguide/resea rchdesigns

Sarybekova, Zh.T. (2004). Osobennosti vospitaniya devochek v kazakhskom narode. 120-121. (Rassilbay A., Trans.). Zhambyl Humanitarian-Technical University, Taraz, Kazakhstan.
Stoller, R.J. (1980). Femininity. In Women's Sexual Development,Kirkpatrick, M. (Ed.) New York \& London:Plenum Press, $127-$ 145.

The things vital for the Kazakhstani youth (2016). Forbes. Retrieved May 7, 2016, from http://forbes.kz/stats/chem_jivet_segodnya _molodej_kazahstana (Original work written in Russian)

Theoretical Framework (2016). In Research Guides of University of Southern California Libraries. (2016). Retrieved May 9, 2016, from http://libguides.usc.edu/writingguide/theor eticalframework

Valuckaite, L. (2014). Construction of Identity and Nightwear Consumption: A Qualitative Study to Explore Danish Females. MA Thesis. Aalborg University, Denmark.

What is Grounded Theory?(2008). Grounded Theory Institute. Retrieved May 7, 2016, from http://www.groundedtheory.com/what-isgt.aspx

Wood, R. (2016). 'You do act differently when you're in it': Lingerie and femininity. Journal of Gender Studies, 25(1), 10-23. Retrieved April 15, 2016, from http://dx.doi.org/10.1080/09589236.2013.8 74942 


\section{ABOUT THE AUTHORS}

Gulnara Z. Karimova, email: gulnara.z.karimova@gmail.com

Dr. Gulnara Z. Karimova is an assistant professor of communication studies at American University of Ras Al Khaimah (UAE) and serves as a marketing consultant to companies in the fashion industry. She received her Ph.D. in Communication and Media Studies at Eastern Mediterranean University (North Cyprus). She is the author of Creativity in Marketing Communications and Bakhtin \& Interactivity: A Conceptual Investigation of Advertising Communication and has published numerous articles in scholarly journals, including the Journal of Brand Strategy, Journal of Marketing Communications, and Journal of Media and Communication Studies.

Ms. Aidana Rassilbay is an associate in the Corporate Development Department at Kcell, the largest cellular operator in Kazakhstan. At the time this research was conducted, she was pursuing a Master's Degree in International Journalism at KIMEP University.

Dr. Daniel A. Sauers earned his Ph.D. in Business Administration with an emphasis in Organizational Behavior and Theory from The Florida State University. Currently, he is serving as a Professor of Management at Winona State University in Winona, Minnesota. Prior to taking up his position at Winona State, he served as the Director for Postgraduate Studies at Lincoln University in Canterbury, New Zealand and the Professor of Management at Al Akhawayn University in Ifrane, Morocco. His research interests lie in the areas of ethics, human resource development and management, international business, leadership, organizational behavior and theory, and strategic management. 
